\title{
Photochromic Dithienylethene- Phenanthroline Ligands and their Corresponding Ru(II) Complexes
}

\author{
Joël Kühni§, Vincent Adamo, and Peter Belser ${ }^{\star}$ \\ $\S S C S$ Poster Prize Winner
}

\begin{abstract}
Dithienylethene-phenanthroline ligands as new photochromic systems are described. The photochemical and photophysical properties are strongly influenced by the substituents on the thiophene moiety. The photochromic properties are lost, if one or two methyl groups in position 2 and/or 2' of the target molecules $(\mathbf{2 o}, \mathbf{3 0}, \mathbf{4 0})$ are replaced by isopropyl groups. Replacement of a methyl group by a phenyl group in position 5 and/or 5 ' shifts the absorption maxima from $514 \mathrm{~nm}$ to $575 \mathrm{~nm}$ for the free ligand (1c, 2c) and from $530 \mathrm{~nm}$ to $613 \mathrm{~nm}$ for the corresponding ruthenium complex $(\mathbf{R u}(\mathbf{1 c}), \mathbf{R u}(\mathbf{2 c}))$ in its closed form. Unfortunately, the photochromic unit in its closed form can be reopened by a back reaction in the dark at room temperature. Complex $\mathbf{R u}(\mathbf{2 0})$ shows an emission with a maximum at $608 \mathrm{~nm}$. The emission is quenched if the metal complex is in its closed form $(\mathbf{R u}(\mathbf{2 c}))$. Fatigue resistance is better for complex $\mathbf{R u}(\mathbf{2 0})$ than for the free ligand (20).
\end{abstract}

Keywords: Energy transfer $\cdot$ Molecular switch $\cdot$ Photochromism $\cdot$ Ruthenium complex $\cdot$ T-junction

\section{Introduction}

Photochromism is a reversible transformation of a single chemical species, being induced in one or both directions by electromagnetic radiation, between two states having different distinguishable absorption spectra. Reversibility of such a bi-stable system is one important criterion for a possible application. The back reaction can occur thermally (T-type) or photochemically (P-type). Photochromic systems can be classified into several categories depending on the chemical transformation induced by light: pericyclic reaction, cis/trans isomerisation, group transfer and others. The dithienylethene type photochromic system can be closed by a 1,6-electrocyclic reaction like in spiropyrans and fulgides [1].

\footnotetext{
${ }^{*}$ Correspondence: Prof. Dr. P. Belser Department of Chemistry

University of Fribourg

Chemin du Musée 9

$\mathrm{CH}-1700$ Fribourg

Tel.: +41263008739

Fax: +41263009738

E-Mail: peter.belser@unifr.ch
}

Organic dithienylethene derivatives have been extensively studied in recent times [2][3]. Properties like ring opening-closing processes, thermal stability, photofatigue resistance, absorption spectra, quantum yield, response time, and others have been frequently reported [2]. On the other hand, dithienylethene derivatives involving metal complexes are rare [4-22]. Most of the dithienylethene switches described in literature need UV light to perform the photocyclisation reaction [2][3]. By introduction of a metal complex, electronic absorption properties are drastically changed by the appearance of the ${ }^{1}$ MLCT transition. It allows the use of visible light to close the switch photochemically by an energy transfer process from the excited metal centre to the dithienylethene moiety (Fig. 1). Therefore, photofatigue resistance can be increased because visible light is usually less destructive than UV light. Moreover, visible light is also employed to reopen the switch, and such a photochromic system works exclusively with Vis-light.

$\left[\mathrm{Ru}(\mathrm{bpy})_{3}\right]^{2+}$ type metal complexes can act as sensitisers, and can therefore be used to induce the desired closing reaction by an energy transfer process. In the present work, a phenanthroline-type ligand has been com-

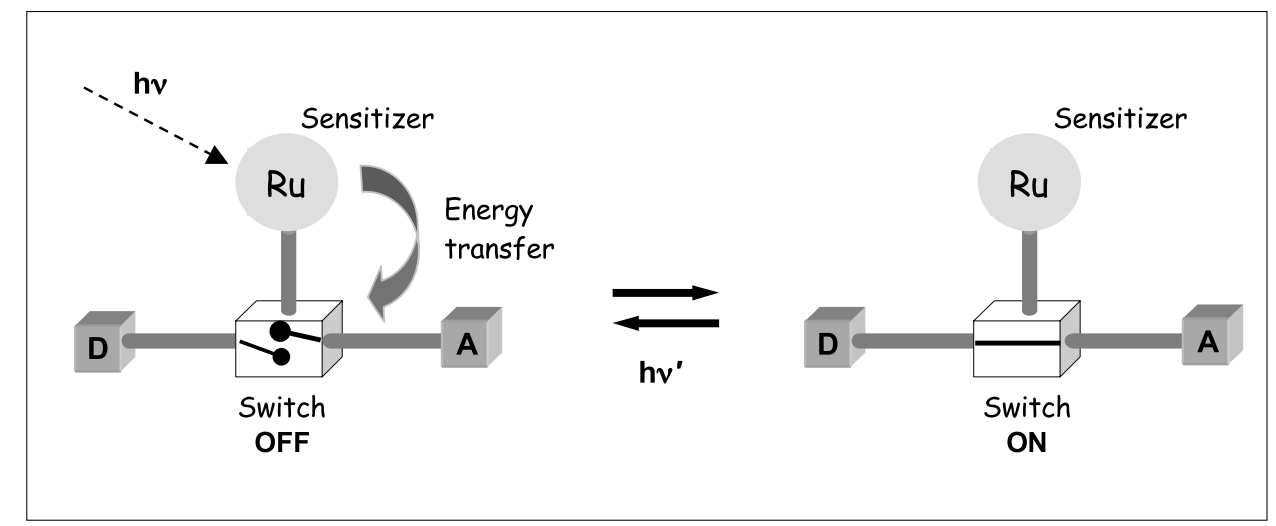

Fig. 1. Schematic illustration of a photochemically active switch driven by a photoinduced energy transfer process. D corresponds to a donor and A to an acceptor unit. 

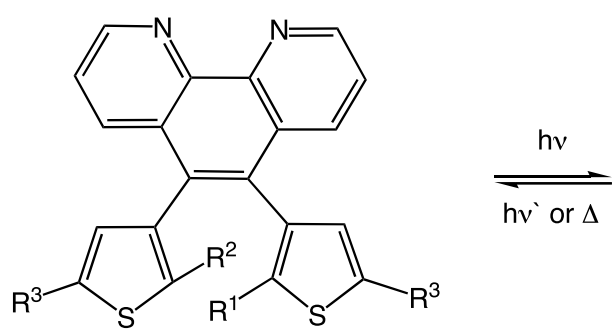

$$
\begin{aligned}
& \text { 10: } R^{1}=R^{2}=R^{3}=M e \\
& \text { 2o }: R^{1}=R^{2}=M e, R^{3}=P h \\
& \text { 3o }: R^{1}=M e, R^{2}=i P r, R^{3}=P h \\
& \text { 4o: } R^{1}=R^{2}=i P r, R^{3}=P h \\
& R u(10)=\left[R u(b p y)_{2}(10)\right]^{2+} \\
& R u(20)=\left[R u(b p y)_{2}(20)\right]^{2+} \\
& R u(30)=\left[R u(b p y)_{2}(30)\right]^{2+}
\end{aligned}
$$

been published [4]. To obtain ligands 3o and 4o, 5,6-dibromo-1,10-phenanthroline was prepared by the method described by Mlochowyski (Scheme) [23]. The corresponding thienyl moieties were synthesised by bromination of 2-methylthiophene and 2-isopropylthiophene (I) [24] each followed by Suzuki coupling with iodobenzene [4]. 5,6-Dibromo-1,10-phenanthroline (VI) was coupled by a Suzuki reaction, first with 2-isopropyl-3-bromo-5-phenylthiophene (III) and then with 2-methyl-5-phenylthiophene-3-boronic acid (IV) to obtain ligand 3o. Ligand 40 was prepared by a double coupling of 2-isopropyl-3-bromo5-phenylthiophene (III) with 5,6-dibromo1,10-phenanthroline (VI). The synthesis of the metal complex $\mathbf{R u}(\mathbf{3 o})$ was performed by following the protocol described in literature [4]. The precursor compound $\mathrm{Ru}(\mathrm{bpy})_{2} \mathrm{Cl}_{2} \cdot 2 \mathrm{H}_{2} \mathrm{O}$ and 30 were heated to reflux in methoxyethanol to yield the complex $\mathbf{R u}(30)$. We did not prepare the metal complex $\mathbf{R u}(\mathbf{4 o})$. The prepared amount of ligand 4o was so small that a further synthetic step was not possible.

During the preparation of the dithienylethene switches two conformers, syn and anti were detected (Fig. 3). In most of the cases described in literature, the thiophene moiety can rotate freely to yield one
In this regard, a new family of ligands (Fig. 2) and their corresponding metal com- plexes $\left[\mathrm{Ru}(\mathrm{bpy})_{2}(\mathrm{~L})\right]^{2+}(\mathrm{L}=\mathbf{1 0}, \mathbf{2 0}, \mathbf{3 o})$ have been synthesised and characterised.

\section{Results and Discussion}

\subsection{Synthesis}

The synthesis of ligands and complexes $10,20, \operatorname{Ru}(10)$ and $\operatorname{Ru}(20)$ have already

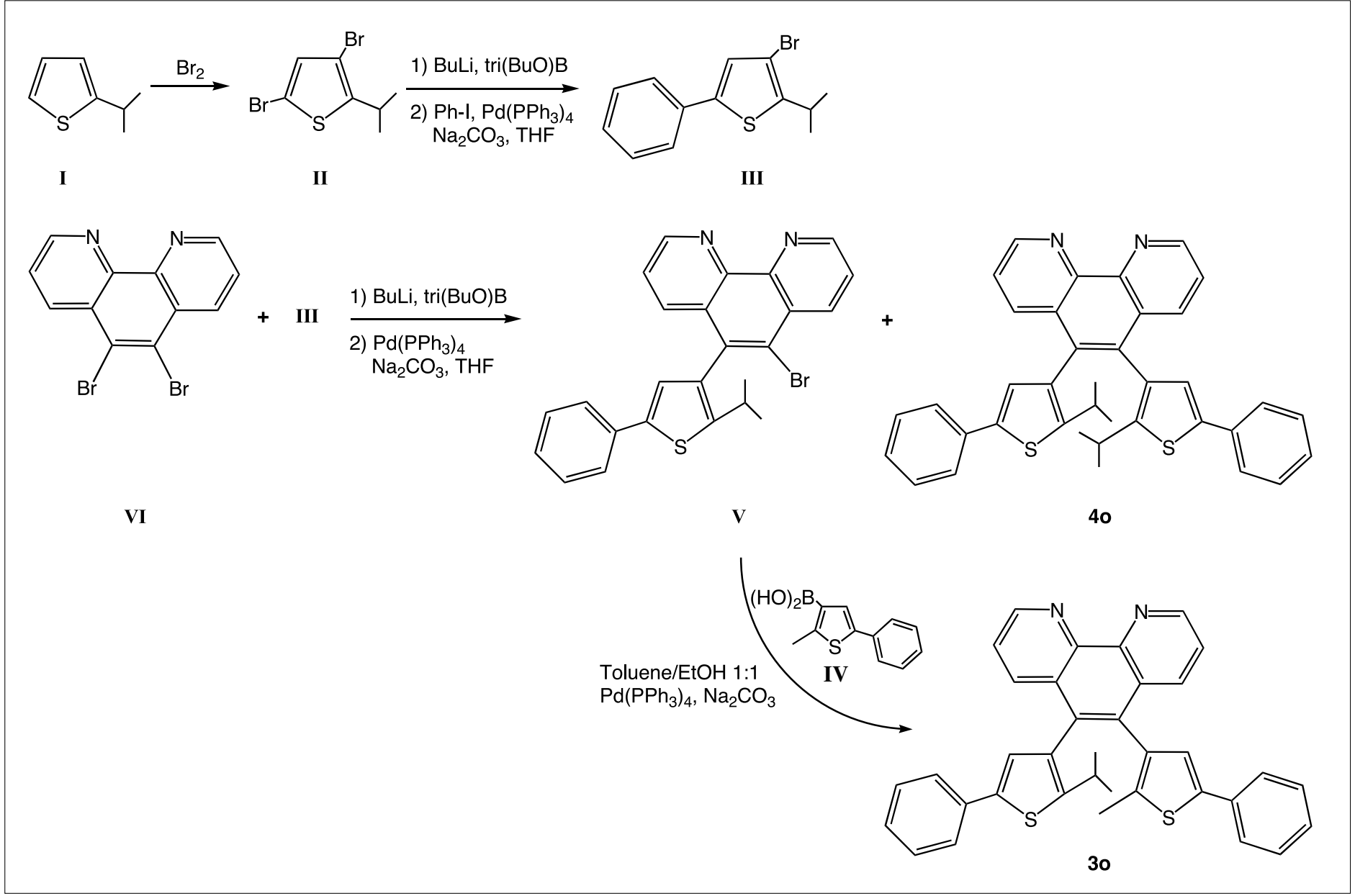



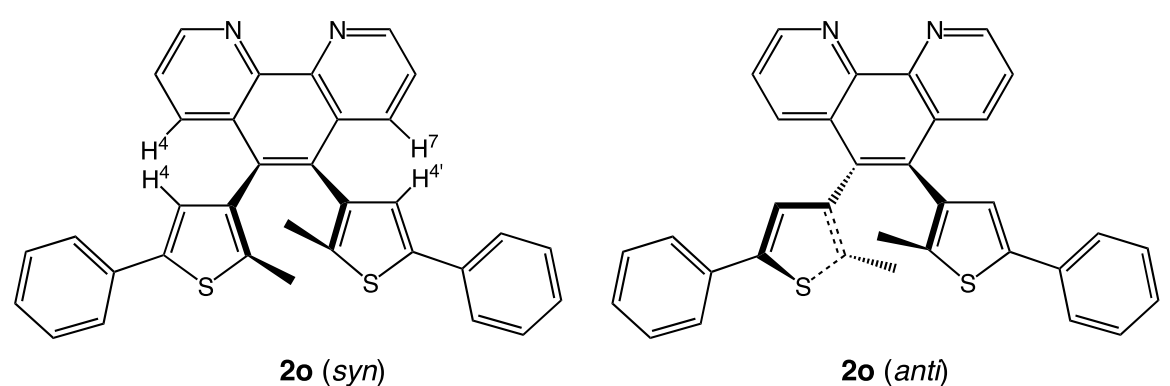

Fig. 3. Syn and anti isomers of ligand 20 set of signals by ${ }^{1} \mathrm{H}-\mathrm{NMR}$ [2][3]. By introduction of a bulky substituent, free rotation is no longer possible and the molecules show two sets of signals by ${ }^{1} \mathrm{H}-\mathrm{NMR}$ [2528], attributed to the syn (photochromic inactive) [29] and anti isomers (photochromic active) [29] as observed for the new ligands 1o, 2o, 30 and 4o. Interconversion between both isomers seems to be blocked at room temperature because of steric hindrance between protons $\mathrm{H}^{4}$ and $\mathrm{H}^{4}$ in the thiophene part and protons $\mathrm{H}^{4}$ and $\mathrm{H}^{7}$ in the phenanthroline unit [5].

The ratio syn/anti can be influenced by $\mathrm{R}^{1}$ and $\mathrm{R}^{2}$ [30], but not by $\mathrm{R}^{3}$ (Table 1 ). ${ }^{1} \mathrm{H}$ NMR analysis does not allow peak attribution for the isomers syn and anti though it does give their ratio.

The photochemical transformation of the photochromic unit from its open to the closed form was performed by irradiation at $254 \mathrm{~nm}$ for the ligands 10 and 20 . The ligands 30 and 40 are photochemically inactive and cannot be closed by such an irradiation process. Irradiation at $450 \mathrm{~nm}$ closed the photochromic unit in the metal complexes $\mathbf{R u}(\mathbf{1 0})$ and $\mathbf{R u}(\mathbf{2 0})$. The metal complex $\mathbf{R u}(\mathbf{3 o})$ is photochemically inactive and exists only in its open form.

The incorporation of the photochromic ligands $\mathbf{1 0}$ and 20 in a metal complex opens a new photochemical pathway for the closing process, which is not observed in the free ligands. Therefore, the closing process can be performed at relatively milder energetic conditions and as a result, the photofatigue resistance increases strongly.

By introduction of an isopropyl group in $\mathrm{R}^{2}$, ligand 30 and complex $\mathbf{R u}(\mathbf{3 o})$ become photo-inert; that is why we have not synthesised the complex $\mathbf{R u}(\mathbf{4 o})$ containing two isopropyl groups. Two explanations can
Table 1

$\begin{array}{lcccc}\text { Ligands: } & \mathbf{1 0} & \mathbf{2 0} & \mathbf{3 0} & \mathbf{4 0} \\ \text { syn/anti ratio } & 1: 1 & 1: 1 & 7: 1 & 6: 1\end{array}$

Table 2

$\begin{array}{ll}\begin{array}{l}\text { Compounds } \\ \text { Ligand }\end{array} & \lambda_{\max }(\mathrm{nm})\left[10^{4} \varepsilon_{\max }\left(\mathrm{M}^{-1} \mathrm{~cm}^{-1}\right)\right]^{\mathrm{a}} \\ \text { 10 } & 232(5.5), 267(2.7) \\ \text { 1c } & 226(3.6), 267(2.2), 360(1.6), 514(0.2) \\ \text { 20 } & 231(2.8), 268(2.6), 294(2.1) \\ \text { 2c } & 230(2.3), 268(2.1), 294(1.8), 389(0.6), 575(0.3) \\ \text { 3o } & 228(2.6), 272(2.3), 282(2.2) \\ \text { 40 } & 229(2.4), 271(2.2), 285(2.1) \\ \text { Complexes } & \\ \text { Ru(1o) } & 285(6.5), 420(1.2), 450(1.5) \\ \mathbf{R u}(1 \mathrm{c}) & 285(6.7), 346(1.0), 420(1.2), 450(1.4), 530(0.2) . \\ \mathbf{R u}(20) & 285(9.6), 421(1.4), 450(1.7) \\ \mathbf{R u ( 2 c )} & 285(9.1), 415(2.1), 450(1.8), 613(0.2) \\ \mathbf{R u ( 3 0 )} & 286(9.2), 420(1.4), 452(1.7)\end{array}$

${ }^{a} \mathrm{MeCN}$ at $293 \mathrm{~K}$. Solution concentration: $10^{-5} \mathrm{M}$. underline this behaviour. Firstly, the closed form of the switching unit is thermally unstable [31-34] and only a small part of the system is present in its closed form. Secondly, the syn/anti ratio of the ligand $\mathbf{3 o}$ was $7 / 1$ and during synthesis, probably the thermodynamically more stable, but photochemically inactive syn conformer was produced as the main compound (Table 1).

\subsection{Absorption Spectra UV/vis}

Absorption maxima and extinction coefficients are reported in Table 2. The absorption spectra of the ligands $\mathbf{1 0}-\mathbf{4 o}$ are similar. The photochromic units of the ligands 10 and 20 can be closed photochemically and the metal complexes $\mathbf{R u}(\mathbf{1 0})$ and $\operatorname{Ru}(\mathbf{1 c})$ have overlapping peaks in their UV/vis spectra. Therefore, only the photochromic systems, 2o/2c and $\mathbf{R u}(\mathbf{2 o}) / \mathbf{R u}(\mathbf{2 c})$, will be discussed.

\subsubsection{Ligand $\mathbf{2 o} / \mathbf{2 c}$}

The UV-spectrum of the open form of ligand 2 shows three transitions in the range $230-300 \mathrm{~nm}$, which can be attributed to the phenanthroline and thiophene moieties (Fig. 4). During irradiation at $254 \mathrm{~nm}$, two new bands arise at $389 \mathrm{~nm}$ and $575 \mathrm{~nm}$ attributable to the closed form of the photochromic switch. Substituents in position 5 at the thiophene unit in its closed form (1c, 2c, $\mathbf{R u}(\mathbf{1 c})$, and $\mathbf{R u}(\mathbf{2 c}))$, influence strongly the energetically lowest absorption band [31][35-39]. For example, the absorption maximum is shifted from $513 \mathrm{~nm}$ for 1c (methyl substituent) to $575 \mathrm{~nm}$ for $2 \mathrm{c}$ (phenyl substituent). An extension of the $\pi$ system can explain such behaviour.

\subsubsection{Metal Complex $\boldsymbol{R u ( 2 o ) / R u ( 2 c )}$}

The absorption spectrum of metal complex $\mathbf{R u}(\mathbf{2 0})$ shows a band at $285 \mathrm{~nm}$ in the UV region (Fig. 5). It can be attributed to the $\pi \rightarrow \pi *$ transition in 2,2'-bipyridine or 1,10 -phenanthroline ligands of the metal complex. In the vicinity of $450 \mathrm{~nm}$, an intense band appears ( ${ }^{1}$ MLCT-transition). After the closing process $\mathbf{R u}(\mathbf{2 c})$, performed by irradiation at $450 \mathrm{~nm}$, two new bands can be observed as was the case with the free ligand. However, the bands are shifted with respect to the free ligand; from $389 \mathrm{~nm} \rightarrow$ $415 \mathrm{~nm}$ and from $575 \mathrm{~nm} \rightarrow 613 \mathrm{~nm}$. The band at $285 \mathrm{~nm}$ has the same intensity in the open and closed forms.

\subsection{Emission Spectra}

Complex $\mathbf{R u}(\mathbf{2 0})$ shows an emission at $608 \mathrm{~nm}$ (Fig. 6) with the excitation wavelength of $450 \mathrm{~nm}$. The emissive band can be attributed to the ${ }^{3}$ MLCT state of the metal complex. If the switching unit is photochemically closed, the intensity of the emission is only decreased by around $17 \%$ but regains the initial intensity in the dark 


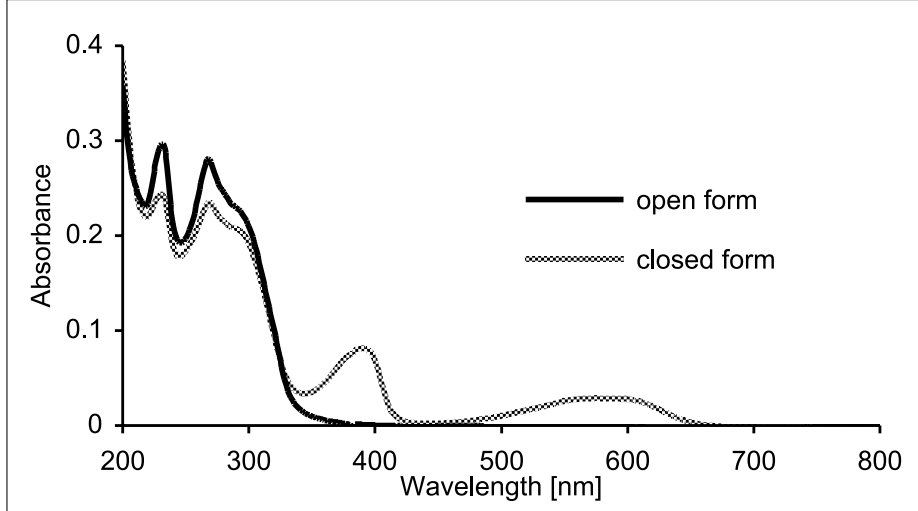

Fig. 4. UV/vis spectra of ligands 20 and $\mathbf{2 c}$

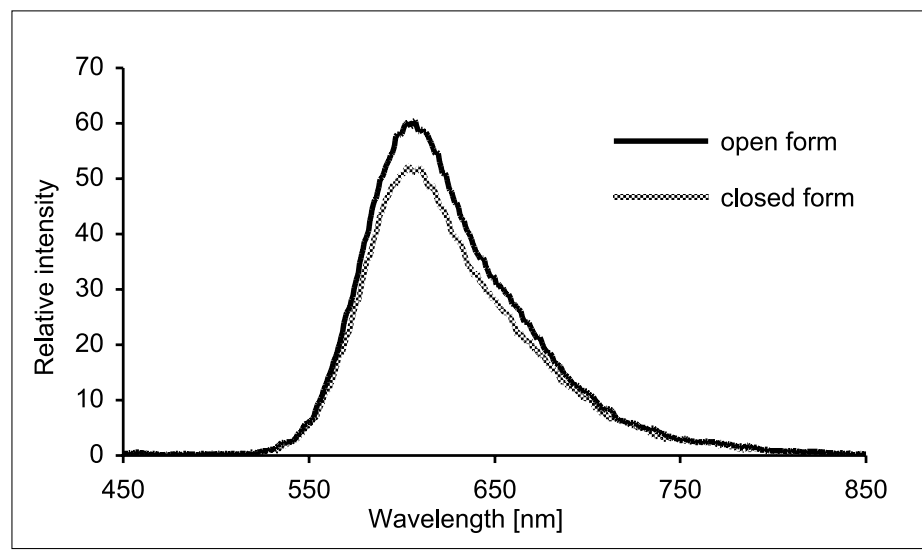

Fig. 6. Emission spectra of complexes $\mathbf{R u}(\mathbf{2 0})$ and $\mathbf{R u}(\mathbf{2 c})$; excitation wavelength $=450 \mathrm{~nm}$

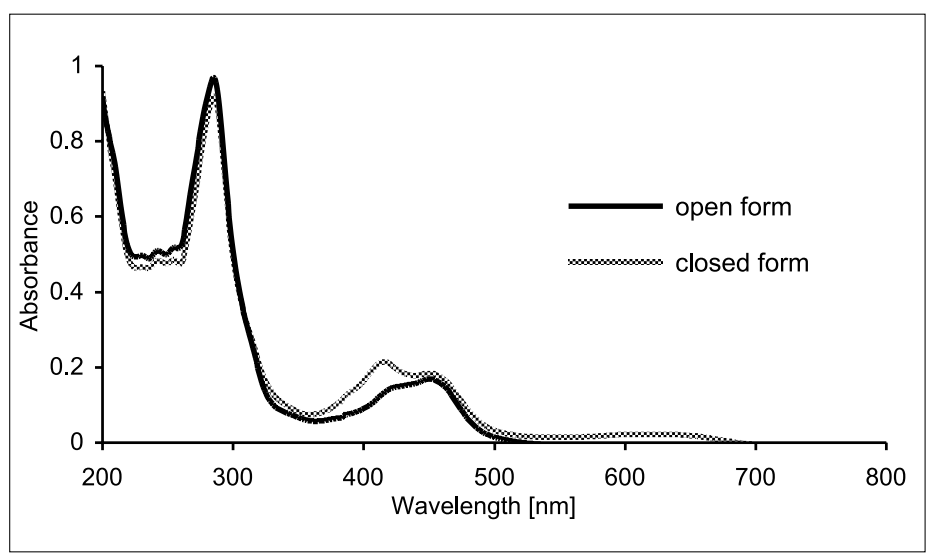

Fig. 5. UV/vis spectra of complexes $\mathbf{R u}(\mathbf{2 0})$ and $\mathbf{R u}(\mathbf{2 c})$

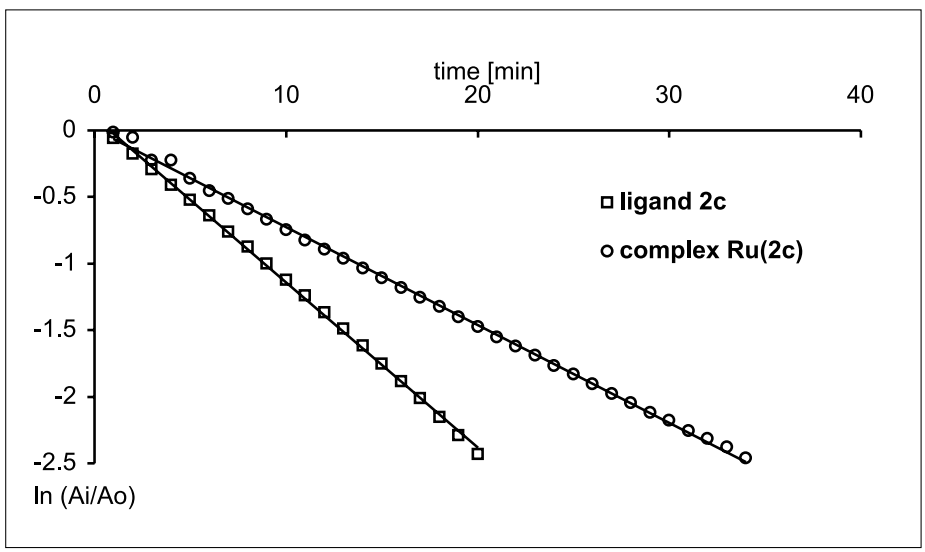

Fig. 7. Thermal stability of ligand $\mathbf{2 c}$ and metal complex $\mathbf{R u}(\mathbf{2 c})$ at room temperature, because the switching unit is thermally reversible. The photostationary state of the closed form $(\operatorname{Ru}(\mathbf{2 c}))$ at room temperature is estimated to be in the range of $20-30 \%$.

The observation that the switching unit of the metal complex $\mathbf{R u}(\mathbf{2 0})$ can be closed by an irradiation at $450 \mathrm{~nm}$, together with the measured emission behaviour, indicates that the energy levels of both triplet states of the ruthenium complex and the switching unit must be similar. By comparison with other photochromic systems [8], we can predict that the metal complex in its pure closed form is non-emissive.

\subsection{Thermal Stability}

Thermal stability deals with the conversion from closed to open form (and vice versa) proceeding spontaneously if the solution of the closed form is kept in the dark.

A thermal process which opens the closed form can be observed for ligands 1c, 2c, and their metal complexes $\mathbf{R u}(\mathbf{1 c})$ and $\mathbf{R u}(\mathbf{2 c})$ (Fig. 7). By measuring the decrease in the intensity of the characteristic band in the visible part of the UV/vis spectrum of ligand 2c, centred at $575 \mathrm{~nm}$, the mentioned opening reaction can be observed. This thermal process has its driving force in the partial lost of aromaticity [40-45], if the double bond between the carbon 5 and 6 in the phenanthroline moiety changes to two exo-double bonds at the same position in the closed form. The reaction rate is determined by applying a first order reaction model. The rate constant and half-lifetime are $0.12 \mathrm{~min}^{-1}$ and $5.6 \mathrm{~min}$, respectively at room temperature. Complex $\mathbf{R u}(\mathbf{2 c})$ shows a similar behaviour to ligand 2c. The absorption band at $613 \mathrm{~nm}$ was chosen to follow the back reaction. The corresponding values are $0.074 \mathrm{~min}^{-1}$ for the rate constant and $9.5 \mathrm{~min}$ for the half-lifetime. The complex $\mathbf{R u}(\mathbf{2 c})$ is more stable than the free ligand $2 \mathrm{c}$ by a factor of 1.7 .

\subsection{Fatigue Resistance}

Photochromic reactions are always accompanied by undesirable side reactions. Consequently, after a certain number of cycles, photochromic properties are altered. This photochromic resistance is essential for practical application.

Fatigue resistance can be measured as following: In deaerated acetonitrile solution, the dithienylethene derivative is irradiated till $90 \%$ of the photostationary state is reached and the coloured closed form is completely bleached. This sequence is repeated several times. After each cycle, absorbance of the coloured compound is measured.

Ligand 20 is closed by irradiation at 254 $\mathrm{nm}$ and reopened with visible light at $600 \mathrm{~nm}$ and shows a deterioration of the photochromic properties after the first cycle. Fatigue resistance is therefore considered lower than other published molecules (Fig. 8) [2].

On the other hand, complex $\mathbf{R u}(\mathbf{2 0})$ closed by irradiation at $450 \mathrm{~nm}$ and reopened with visible light at $600 \mathrm{~nm}$ shows quasi-constant photochromic properties after a few cycles (Fig. 9).

By using an irradiation wavelength of $450 \mathrm{~nm}$, the fatigue resistance has been enhanced. The alternative path of energy transfer from the excited ${ }^{3} \mathrm{MLCT}$ state of the ruthenium metal complex to the triplet state of the switching unit occurs under much milder condition compared to the corresponding irradiation at $254 \mathrm{~nm}$ and no other photochemical side reaction lowers the fatigue resistance.

\section{Conclusions}

A new series of dithienylethene-phenanthroline ligands and their ruthenium complexes ([Ru(bpy) $)_{2}$ (ligand) $\left.]\left(\mathrm{PF}_{6}\right)_{2}\right)$ has been prepared and studied. Ligand 20 and 


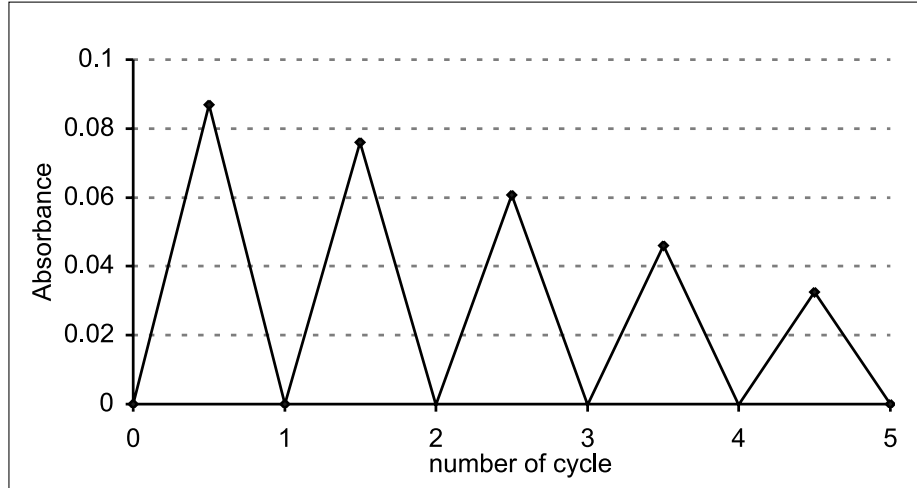

Fig. 8. Photofatigue resistance of ligand 20

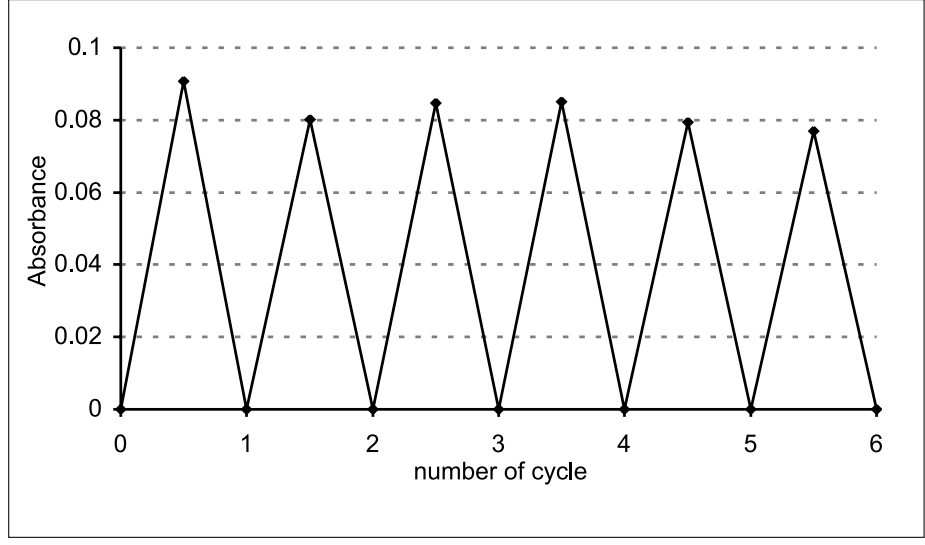

Fig. 9. Photofatigue resistance of metal complex $\mathbf{R u}(\mathbf{2 0})$ complex $\mathbf{R u}(\mathbf{2 0})$ have the most promising photochromic properties, which are limited by the presence of two isomers syn and anti, because only the anti conformer is photochemically active and undergoes the photocyclisation reaction. Moreover, an interconversion between the two isomers syn and anti is sterically blocked.

Complex $\mathbf{R u}(\mathbf{2 0})$ has a better fatigue resistance and is thermally more stable than the free ligand 2o. The complex $\operatorname{Ru}(\mathbf{2 o})$ shows an emission whereas its closed form is non-emissive.

\section{Acknowledgements}

We thank the Swiss National Science Foundation for funding through the NFP47 program.

Received: January 18, 2006

[1] H. Dürr, H. Bouas-Laurent, 'Photochromism: Molecules and Systems', Elsevier, Amsterdam, 1990.

[2] M. Irie, Chem. Rev. 2000, 100, 1685.

[3] H. Tian, S. Yang, Chem. Soc. Rev. 2004, 33,85 .

[4] P. Belser, L. De Cola, F. Hartl, V. Adamo, B. Bozic, Y. Chriqui, V. Mahadevan Iyer, R.T.F. Jukes, J. Kühni, M. Querol, S. Roma, N. Salluce, Adv. Funct. Mater. 2006, 195.

[5] V.W.-W. Yam, C.-C. Ko, N. Zhu, J. Am. Chem. Soc. 2004, 126, 12734.

[6] R.T.F. Jukes, V. Adamo, F. Hartl, P. Belser, L. De Cola, Coord. Chem. Rev. 2005, 249, 1327.

[7] R.T.F. Jukes, V. Adamo, F. Hartl, P. Belser, L. De Cola, Inorg. Chem. 2004, 43, 2779.

[8] V. Adamo, P. Belser, Chimia 2003, 57, 169.

[9] S. Fraysse, C. Coudret, J.-P. Launay, Eur. J. Inorg. Chem. 2000, 1581.

[10] A. Fernandez-Acebes, J.-M. Lehn, Chem.Eur. J. 1999, 5, 3285.

[11] A. Fernandez-Acebes, J.-M. Lehn, $A d v$. Mater. 1998, 10, 1519.

[12] M. Takeshita, M. Irie, J. Org. Chem 1998, 63, 6643 .
[13] M. Takeshita, M. Irie, Tetrahedron Lett. 1998, 39, 613.

[14] M. Munakata, L.P. Wu, T. Kuroda-Sowa, Bull. Chem. Soc. Jpn. 1997, 70, 1727.

[15] D. Sud, R. McDonald, N.R. Branda, Inorg. Chem. 2005, 44, 5960.

[16] H.D. Samachetty, N.R. Branda, Chem. Commun. 2005, 2840.

[17] H. Tian, B. Chen, H. Tu, K. Mullen, $A d v$. Mater. 2002, 14, 918.

[18] B. Chen, M. Wang, Y. Wu, H. Tian, Chem. Commun. 2002, 1060.

[19] E. Murguly, T.B. Norsten, N.R. Branda, Angew. Chem. Int. Ed. 2001, 40, 1752.

[20] K. Matsuda, K. Takayama, M. Irie, Chem. Commun. 2001, 363.

[21] K. Matsuda, K. Takayama, M. Irie, Inorg. Chem. 2004, 43, 482.

[22] H. Konaka, L.P. Wu, M. Munakata, T. Kuroda-Sowa, M. Maekawa, Y. Suenaga, Inorg. Chem. 2003, 42, 1928.

[23] J. Mlochowski, J. Rocz. Chem. 1974, 48, 2145.

[24] M.R. Detty, D.S. Hays, Heterocycles 1995, 40, 925.

[25] K. Uchida, E. Tsuchida, Y. Aoi, S. Nakamura, M. Irie, Chem. Lett. 1999, 63.

[26] K. Uchida, E. Tsuchida, S. Nakamura, S. Kobatake, M. Irie, Mol. Cryst. and Liq. Cryst. 2000, 345, 9.

[27] M. Irie, K. Sakemura, M. Okinaka, K. Uchida, J. Org. Chem. 1995, 60, 8305.

[28] K. Uchida, Y. Nakayama, M. Irie, Bull. Chem. Soc. Jpn. 1990, 63, 1311.

[29] R. Hoffmann, R.B. Woodward, J. Am Chem. Soc. 1965, 87, 2046.

[30] K. Uchida, D. Guillaumont, E. Tsuchida, G. Mochizuki, M. Irie, A. Murakami, S. Nakamura, Theochem. 2002 , 579, 115.

[31] S. Kobatake, M. Irie, Chem. Lett. 2003, 32, 1078.

[32] K. Morimitsu, K. Shibata, S. Kobatake, M. Irie, Chem. Lett. 2002, 572.

[33] S. Kobatake, K. Shibata, K. Uchida, M. Irie, J. Am. Chem. Soc. 2000, 122 12135 .

[34] S. Kobatake, K. Uchida, E. Tsuchida, M. Irie, Chem. Lett. 2000, 1340.
[35] K. Higashiguchi, K. Matsuda, Y. Asano, A. Murakami, S. Nakamura, M. Irie, Eur. J. Org. Chem. 2005, 91.

[36] S.-Z. Pu, F.-S. Zhang, F. Sun, R.-J. Wang, X.-H. Zhou, S.-K. Chan, Tetrahedron Lett. 2003, 44, 1011.

[37] S.L. Gilat, S.H. Kawai, J.-M. Lehn, Chem Commun. 1993, 1439.

[38] K. Uchida, M. Irie, Chem. Lett. 1995 , 969.

[39] S.L. Gilat, S.H. Kawai, J.-M. Lehn, Chem.Eur. J. 1995, 1, 275.

[40] S. Nakamura, M. Irie, J. Org. Chem. 1988, 53,6136 .

[41] C.W. Bird, Tetrahedron 1997, 53, 13111.

[42] T.M. Krygowski, M.K. Cyranski, Z Czarnocki, G. Hafelinger, A.R. Katritzky, Tetrahedron 2000, 56, 1783.

[43] T.M. Krygowski, M.K. Cyranski, Tetrahedron 1996, 52, 10255.

[44] T.M. Krygowski, M.K. Cyranski, Tetrahedron 1996, 52, 1713.

[45] T.M. Krygowski, M.K. Cyranski, Chem. Rev. 2001, 101, 1385. 